\title{
Sofía MERCADER
}

Universidad Nacional Autónoma de México, UNAM, México.

sofiamercader@gmail.com

ORCID iD: http://orcid.org/0000-0003-1603-5753

Recibido: 28/10/2020 - Aceptado: $31 / 01 / 2021$

Para citar este artículo / To reference this article / Para citar este artigo

Mercader, Sofía. "Lógica militarista y nacionalista versus subjetividad antinacionalista. Los debates intelectuales en torno a la Guerra de Malvinas en la revista Punto de Vista". Humanidades: revista de la Universidad de Montevideo, n 9, (2021): I23-146.

https://doi.org/l0.25185/9.6

\section{Lógica militarista y nacionalista versus subjetividad antinacionalista. Los debates intelectuales en torno a la Guerra de Malvinas en la revista Punto de Vista ${ }^{1}$}

\begin{abstract}
Resumen: Este artículo se propone examinar las discusiones intelectuales que se dieron en Argentina en el contexto de la Guerra de Malvinas (1982), haciendo énfasis en la posición adoptada por la revista Punto de Vista (1978-2008). Los objetivos de este artículo son, por una parte, analizar el conflicto de Malvinas en su contexto histórico para, luego, examinar y complejizar la postura sostenida por el grupo de Punto de Vista, que se opuso categóricamente a la invasión militar, sosteniendo así una posición minoritaria dentro del campo intelectual. El artículo sostiene que estas figuras (cuyas voces más salientes fueron las de Carlos Altamirano y Beatriz Sarlo) adoptaron una posición antinacionalista y de oposición al régimen militar, mientras que otros intelectuales igualmente opuestos a la dictadura hicieron caso omiso de los factores contextuales de la guerra y apoyaron el conflicto. A partir del análisis de artículos publicados en Punto de Vista, otros escritos aparecidos en otras revistas de la época y correspondencia personal de los intelectuales estudiados, el artículo también demuestra cómo el grupo de Punto de Vista relacionó la derrota de Malvinas con la transición a la democracia, precipitada por el fin de la guerra a mediados de 1982 y cómo a lo largo de los años insistió, desde la misma posición antinacionalista y minoritaria, en la necesidad de revisar el momento patriótico de 1982 críticamente.
\end{abstract}

Palabras clave: Guerra de Malvinas, Punto de Vista, intelectuales, Argentina. 


\title{
Militarist and nationalist logic versus antinationalist subjectivity intellectual debates on the Malvinas war in the magazine Punto de Vista
}

\begin{abstract}
This article aims to examine the intellectual discussions that took place in Argentina in the context of the Malvinas War (1982), emphasizing the position adopted by the magazine Punto de Vista (1978-2008). The objectives of this article are, on the one hand, to analyse the Malvinas conflict in its historical context and, on the other hand, to examine the position held by the Punto de Vista group, which categorically opposed the military invasion, thus holding a minority position within the intellectual field. The article argues that these figures (whose most salient voices were those of Carlos Altamirano and Beatriz Sarlo) adopted an anti-nationalist position and opposed the military regime, while other intellectuals on the left ignored the contextual factors of the war and supported the conflict. Based on the analysis of articles published in Punto de Vista, articles that appeared in other magazines of the time and personal correspondence of the intellectuals studied, the article also shows how the Punto de Vista group related the Malvinas defeat to the transition to democracy, precipitated by the end of the war in mid-1982, and how over the years they insisted, from the same anti-nationalist and minority position, on the need to critically review the patriotic moment of 1982.
\end{abstract}

Keywords: Malvinas War, Punto de Vista, intellectuals, Argentina.

\section{Lógica militarista e nacionalista versus subjetividade antinacionalista. Debates intelectuais em torno da Guerra das Malvinas na revista Punto de Vista}

Resumo: Este artigo tem como objetivo examinar as discussões intelectuais ocorridas na Argentina no contexto da Guerra das Malvinas (1982), destacando a posição adotada pela revista Punto de Vista (1978-2008). Os objetivos deste artigo são, por um lado, analisar o conflito das Malvinas no seu contexto histórico e, em seguida, examinar e complicar a posição do grupo Punto de Vista, que se opôs categoricamente à invasão militar, detendo assim uma posição minoritária no interior do campo intelectual. 0 artigo argumenta que essas figuras (cujas vozes mais salientes foram as de Carlos Altamirano e Beatriz Sarlo) adotaram uma posição antinacionalista e de oposição ao regime militar, enquanto outros intelectuais igualmente contrários à ditadura ignoraram os fatores contextuais da guerra e eles apoiaram o conflito. Da análise dos artigos publicados em Punto de Vista, outros escritos que apareceram em outras revistas da época e correspondência pessoal dos intelectuais estudados, 0 artigo também mostra como o grupo de Punto de Vista relacionou a derrota de Malvinas com a transição para a democracia, precipitada pelo fim da guerra em meados de 1982 e como ao longo dos anos insistiu, a partir da mesma posição anti-nacionalista e minoritária, na necessidade de rever criticamente o momento patriótico de 1982.

Palavras-chave: Guerra das Malvinas, Punto de Vista, intelectuais, Argentina. 
El 6 de mayo de 1982, la revista argentina Gente publicó un número especial cuya tapa estaba ilustrada con una fotografía de soldados argentinos en posición de combate, acostados en el suelo y empuñando rifles, junto con el título «Estamos ganando». ${ }^{2}$ Se trataba de la cobertura de la Guerra de Malvinas, el único conflicto bélico de la historia argentina moderna. La tapa de Gente quedaría en el recuerdo colectivo como un símbolo de la tergiversación que la prensa y el gobierno militar hicieron de la guerra y como la constatación de un entramado de ardides, intereses y manipulaciones que sólo el fin del conflicto pondría al descubierto.

Podría decirse que, si algo condensó la Guerra de Malvinas a principios de la década del ochenta, cuando la dictadura militar que había tomado el poder en 1976 aún estaba en pie, fue confusión. Dicha confusión se explica por la falta de distinción entre los motivos que impulsaron al gobierno militar a entrar en conflicto con el Reino Unido, por un lado, y, por el otro, la legitimidad del reclamo por la soberanía de las islas. En otras palabras, se superponían los motivos relacionados con la política interior de la dictadura militar con el histórico reclamo por la soberanía nacional sobre un territorio dominado por los vestigios de un poder colonial. Durante los meses que duró el conflicto, los medios de comunicación de masas en Argentina se mantuvieron en su gran mayoría alineados con el gobierno - como lo atestigua la tapa de la revista Gente - y realizaron una cobertura que hasta pocos días antes del fin de la guerra mostraba a la Argentina como vencedora. Sin embargo, existieron, durante los últimos años de la dictadura, intersticios a través de los cuales algunas voces disidentes pudieron expresarse.

Este artículo se centra en el tratamiento del conflicto de Malvinas por parte de los intelectuales nucleados alrededor de la revista Punto de Vista (1978-2008), quienes rechazaron la ofensiva de parte del gobierno argentino y ofrecieron argumentos contra la guerra desde una posición minoritaria. Contra el fervor nacionalista que profesaron amplios sectores de la sociedad, incluida la mayoría de los partidos políticos, los sindicatos y grupos de izquierda, los intelectuales de Punto de Vista se opusieron al conflicto en base a un análisis crítico de la decisión militar, invocando la necesidad de contextualizar históricamente la guerra y de rechazar el nacionalismo fomentado por dicha coyuntura. El objetivo de este artículo es examinar esta postura minoritaria durante el conflicto de Malvinas con el fin de analizar qué tipo de argumentaciones se sostuvieron en el campo intelectual argentino durante la guerra. En particular, 
se pondrán de relieve las discusiones que los intelectuales asociados a la revista sostuvieron con otros intelectuales en el exilio y se analizarán las menciones a Malvinas en Punto de Vista. Estos aspectos son importantes para comprender, asimismo, el final de la dictadura militar argentina luego de la derrota en el Atlántico Sur, la que dio inicio a la transición a la democracia de 1983.

Así, el artículo ofrecerá una contextualización histórica del conflicto de Malvinas, en tanto las posiciones intelectuales respecto del conflicto no pueden comprenderse sin hacer referencia a dicho contexto. Luego ubicará a Punto de Vista dentro del grupo de publicaciones independientes de la época. Se analizarán con detalle los argumentos esgrimidos contra la guerra por los miembros de la revista en una declaración publicada en el semanario Nueva Presencia, en correspondencias personales y en artículos en Punto de Vista. Se contrastará esta postura con el apoyo a la guerra expresado por otros grupos de intelectuales de izquierda exiliados en México y cercanos a Punto de Vista. Finalmente, se ofrecerán algunas líneas de interpretación acerca de cómo repercutieron estas discusiones en los años posteriores a la transición en Argentina.

\section{Los militares argentinos van a la guerra}

El 2 de abril de 1982 las Fuerzas Armadas argentinas tomaron control de Puerto Stanley, rebautizado Puerto Argentino, en declaración de guerra con el Reino Unido, país que desde 1833 ocupa estas islas del Atlántico Sur. Argentina se encontraba bajo uno de los regímenes más represivos de su historia contemporánea, instalado en 1976 bajo el nombre de «Proceso de reorganización nacional», uno de cuyos rasgos más salientes fue la violación sistemática de los derechos humanos, la cual dejó un saldo de entre 9 mil y 30 mil víctimas directas. ${ }^{3}$ Bajo el argumento de que estaban librando una guerra

3 Existe una amplia bibliografía sobre la cuestión de los derechos humanos en la Argentina durante la época de la dictadura y la postdictadura. Entre los trabajos más importantes se encuentran Pilar Calveiro, Poder y desaparición: los campos de concentración en Argentina (Buenos Aires: Colihue, 1998); Emilio A. Crenzel, La historia politica del Nunca más: la memoria de las desapariciones en la Argentina (Buenos Aires: Siglo Veintiuno Editores, 2008); Elizabeth Jelin, Los trabajos de la memoria (Madrid: Siglo Veintiuno Editores, 2002); Hugo Vezzetti, Pasado y presente: guerra, dictadura y sociedad en la Argentina (Buenos Aires: Siglo Veintiuno Editores, 2002). Existen también importantes controversias respecto de la interpretación histórica de este período, una de cuyas más salientes disputas está relacionada con el número de víctimas directas de la represión. Mencionamos por ello el cálculo más conservador de nueve mil víctimas (según el reporte de la Comisión Nacional por la Desaparición de Personas, publicado bajo el título Nunca Más) y el de treinta mil, que es el número que muchas organizaciones de derechos humanos consideran correcto. 
contra el enemigo interno, identificado como la «izquierda subversiva», los militares impusieron la persecución de todo movimiento político de izquierda y la cultura estuvo ampliamente sujeta a censura. Periódicos y revistas dejaron de publicarse, decenas de miles de personas partieron al exilio y la sociedad entera estuvo sometida al control estricto del gobierno dictatorial. ${ }^{4}$

¿Por qué la junta militar, que justificaba su gobierno bajo el argumento de la guerra interna, se embarcó en un conflicto bélico contra una de las mayores potencias mundiales en 1982? Las razones de esta decisión deben buscarse en una serie de crisis que, tanto en el plano interno como en el externo, enfrentaba el gobierno militar. En el plano doméstico, a una serie de disputas al interior de la cúpula militar, se le sumó una crisis económica de grandes dimensiones derivada de las políticas implementadas por el ministro de economía Alfredo Martínez de Hoz entre 1976 y 1981, las cuales condujeron a una aguda reducción de las reservas, la devaluación de la moneda y una caída del producto bruto interno, la manufactura y los salarios. ${ }^{5}$ En el ámbito de política exterior, las denuncias por violaciones a los derechos humanos a principios de los ochenta comenzaron a minar la ambición de los militares de permanecer en el poder. En marzo de 1980, la Comisión Interamericana de Derechos Humanos, luego de una visita al país, publicó un reporte que denunciaba la represión en Argentina y advertía que miles de ciudadanos habían sido detenidos, torturados y desaparecidos por comandos militares. ${ }^{6}$ El reporte llevó a un plano internacional los reclamos de las asociaciones de derechos humanos que habían comenzado a organizarse en Argentina desde los primeros años de la dictadura. Pese a que los militares negaron las acusaciones del reporte de la CIDH y la mayoría de los medios de prensa locales mantuvieron la complicidad con el régimen, el reporte fue difundido por la prensa internacional, dando lugar a que se conocieran las atrocidades cometidas por el régimen.

En síntesis, hacia fines de 1981 los militares argentinos se encontraban encerrados en una aguda crisis económica y política y asediados por un

4 Para una breve descripción de la censura cultural durante la época de la dictadura ver Natalia Milanesio, ¡Destape! sex, democracy, \& freedom in postdictatorial Argentina (Pittsburgh: University of Pittsburgh Press, 2019) y Andrés Avellaneda, "Argentina militar: Los discursos del silencio", en Literatura argentina hoy: de la dictadura a la democracia, ed. Karl Kohut y Andrea Pagni (Frankfurt am Main: Vervuert, 1993).

5 En 1982, la cúpula militar se encontraba fracturada entre una facción que favorecía la salida democrática, liderada por el General Roberto Viola, y otra que proponía perpetuarse en el poder, liderada por el General Leopoldo Fortunato Galtieri, quien asumió la presidencia en 1981.

6 El reporte completo de la CIDH se encuentra disponible en el sitio de la Comisión Interamericana de Derechos Humanos: http://www.cidh.oas.org/countryrep/Argentina80sp/indice.htm 
descrédito internacional cada vez mayor. La mayoría de los partidos políticos argentinos, ante la posibilidad de una transición democrática en el horizonte, comenzaron a organizarse a través de la fundación de la Multipartidaria en 1981. ${ }^{7}$ El general Leopoldo Fortunato Galtieri que presidía el país en 1982, se embarcó en una última aventura militar con vistas a atraer el apoyo político de la sociedad argentina y alinear las disputas dentro de las Fuerzas Armadas a través de la ocupación de las Islas Malvinas. El reclamo por la soberanía territorial tenía un importante peso simbólico, dado que se trataba de un reclamo territorial de larga data, fuertemente arraigado en el sentido de nacionalidad de la sociedad argentina. Los militares creyeron que la ofensiva traería consigo el apoyo unánime de las grandes mayorías y que, por otra parte, el Reino Unido no se embarcaría en un conflicto bélico internacional por un territorio tan pequeño y escasamente poblado.

En un comienzo, la junta acometió su objetivo inmediato de atraer apoyo popular, ya que miles de personas se congregaron el 2 de abril en la emblemática Plaza de Mayo en señal de apoyo a la aventura militar. La misma plaza había sido unos días antes escenario de una brutal represión por parte del gobierno contra una manifestación opositora de la Confederación General del Trabajo, lo que evidenciaba hasta qué punto parte de la sociedad adhirió a la causa Malvinas con un fervor inusitado. ${ }^{8}$ En efecto, la declaración de guerra contra el Reino Unido fue apoyada por numerosos sectores, incluidos los partidos políticos de izquierda, tales como el Partido Comunista, los partidos trotskistas y Montoneros, la agrupación peronista guerrillera cuyos líderes se encontraban en su mayoría en el exilio. Los dos principales partidos políticos, el Partido Justicialista (Peronista) y la Unión Cívica Radical, así como los otros partidos que formaban parte de la Multipartidaria, también celebraron la ocupación del archipiélago por parte del ejército argentino. Sólo algunas voces aisladas se manifestaron en disidencia, como fue el caso de Adolfo Pérez Esquivel, Premio Nobel de la Paz y director de la organización de derechos humanos Servicio de Paz y Justicia. Raúl Alfonsín, quien sería electo presidente en 1983 como candidato de la Unión Cívica Radical, también se opuso al conflicto y denunció la actitud de los principales partidos políticos,

7 La Multipartidaria estaba conformada por los siguientes partidos: La Unión Cívica Radical, el Partido Justicialista (peronista), el Partido Intransigente (de izquierda), el Partido Demócrata Cristiano y el Movimiento de Integración y Desarrollo.

8 La manifestación por Malvinas se considera, junto con las celebraciones populares con motivo del triunfo argentino en el mundial de fútbol de 1978, reflejo de una cierta complicidad de la sociedad civil respecto del régimen dictatorial. Para un estudio exhaustivo de la actitud de la sociedad civil respecto del régimen militar ver David M. K Sheinin, Consent of the Damned: Ordinary Argentinians in the Dirty War (Gainesville: University Press of Florida, 2013). 
incluido el suyo, acusándolos de estar imponiendo un «cepo patriótico» que impedía cualquier tipo de disenso respecto del tema Malvinas. ${ }^{9}$

A pesar de que los militares suponían que el conflicto no derivaría en una guerra, el Reino Unido, bajo la primera magistratura de Margaret Thatcher, envió rápidamente la flota británica a las islas y se aseguró el apoyo del Consejo de Seguridad de las Naciones Unidas, que declaró a la Argentina nación agresora y exigió el retiro de las tropas. En un primer momento, Estados Unidos intentó ofrecer una mediación a través del secretario de Estado Alexander Haig. Sin embargo, cuando los británicos comenzaron a atacar a los soldados argentinos en las islas, Estados Unidos retiró su mediación y se alineó con su aliado europeo. La junta militar quedaba así aislada diplomáticamente y en desventaja respecto de su contrincante, superior en logística y preparación para el combate. Mientras que en Buenos Aires los medios ofrecían una cobertura heroica de la guerra, en las islas las tropas sufrían crecientes pérdidas, falta de provisiones y una generalizada desmoralización. ${ }^{10}$ Luego de 74 días de combate en los cuales 649 soldados argentinos y 258 soldados británicos perdieron la vida, la guerra concluyó el 14 de junio de 1982 con la rendición final de Argentina frente al Reino Unido.

En el ámbito intelectual se reprodujeron las mismas disputas que se dieron entre las figuras políticas mencionadas más arriba en tanto un sector mayoritario apoyó la guerra, mientras que uno minoritario la rechazó. Como veremos más abajo, la expresión «cepo patriótico» utilizada por Alfonsín sintetizaba el estado de situación de la opinión pública argentina en 1982: había poco espacio para la disidencia respecto de la guerra y el fervor nacionalista marcó los límites de lo que podía o no expresarse respecto de Malvinas. Vale la pena aquí adelantar lo que Horacio Tarcus identificó como una disputa que se dirimió entre una «lógica militarista y nacionalista», sostenida por una mayoría, y una «subjetividad antinacionalista», apoyada por un grupo reducido. ${ }^{11}$ Aún quienes se oponían fervientemente a los militares, asumieron la primera de estas lógicas, la militarista-nacionalista, y solo pocos intelectuales - como aquellos congregados en la revista Punto de Vista- se opusieron al clima nacionalista y patriótico que suscitó la guerra.

9 El término «cepo patriótico» se le atribuye a Alfonsín en Beatriz Sarlo, "La memoria de la Guerra de Malvinas sigue siendo inabordable como mito nacional. El patriotismo despótico”, La Nación, 27 enero de 2012, https:/ / www.lanacion.com.ar/opinion/el-patriotismo-despotico-nid1443722/.

10 Luis Alberto Romero, Breve historia contemporánea de la Argentina. 1916-2016 (México: Fondo de Cultura Económica, 2017), 270.

11 Horacio Tarcus, “Los dilemas de la izquierda en la Guerra de Malvinas”, Página 12, 2 de abril de 2007. 
Es sin dudas paradójico que, en el momento en que los crímenes de estado de la dictadura comenzaron a tomar estado público, grandes sectores de la sociedad hayan apoyado la iniciativa bélica bajo la idea de que la importancia del reclamo soberano pesaba más que la circunstancia histórica en que se inscribía la guerra. Aún más, incluso intelectuales en el exilio apoyaron la ofensiva.

\section{Revistas en la encrucijada bélica y el caso de Punto de Vista}

Los estudios sobre revistas culturales e intelectuales durante la Guerra de Malvinas son escasos. Entre los estudios más recientes, pueden señalarse el trabajo de Mara Burkart sobre la revista Humor, el de Cora Gamarnik sobre la revista Gente, el de Exequiel Svelitza sobre la revista Sitio y los de Ignacio Moretti, Mariano Veliz y Alberto Bonnet sobre las posturas de los intelectuales de izquierda frente al conflicto bélico. ${ }^{12}$ Si bien Punto de Vista es una revista que ha recibido la atención de numerosos estudios, solo Moretti la ha puesto en relación con las disputas intelectuales sobre Malvinas. ${ }^{13}$ Sin embargo, Moretti analiza brevemente tan sólo uno de los artículos aparecidos en la revista sobre la guerra, mientras que en las páginas siguientes nos proponemos indagar sobre la discusión más general que se dio en el ámbito de las publicaciones

12 Mara E. Burkart, "Avatares de la crítica y de la sátira: HUMOR y la Guerra de Malvinas", Nuevo mundo. Mundos nuevos, 7 de febrero de 2013; Cora Gamarnik, "La fotografía de prensa durante la guerra de Malvinas: la batalla por lo (in)visible”, Páginas (Rosario): Revista Digital de la Escuela de Historia 7, nº 13 (2015): 79-117; Exequiel Svetliza, "La guerra de Malvinas y sus trincheras intelectuales: entredichos entre los editores de la revista Sitio y el escritor Néstor Perlongher", Remate de Males 37, no 2 (2017): 925-44; Ignacio Moretti, "De silencios, diatribas y apoyos. Los intelectuales de izquierda frente a la Guerra de Malvinas", Estudios Sociales: Revista Universitaria Semestral 54, $\mathrm{n}^{\circ}$ 1 (2018): 169-192; Mariano Veliz, "Formas discrepantes de inteligibilidad de la Guerra de Malvinas: Jorge Denti y León Rozitchner entre el exilio y la subjetividad", Nuevo mundo. Mundos nuevos, 8 de octubre de 2019; Alberto Bonnet, "La izquierda argentina y la guerra de las Malvinas", Razón y Revolución, no 3 (7 de septiembre de 2014), http://www.revistaryr.org.ar/index.php/RyR/article/view/456.

13 Sobre Punto de Vista, consultar John King, "Las revistas culturales de la dictadura a la democracia: el caso de 'Punto de Vista', en Literatura argentina hoy: de la dictadura a la democracia, ed. Karl Kohut y Andrea Pagni (Frankfurt: Vervuert, 1993), 87-94; Sofía Mercader, "Notas sobre la historia de la revista Punto de Vista (1978-2008) y su colocación en el campo intelectual argentino de fin de siglo", Nuevo mundo. Mundos nuevos, 16 de febrero de 2018; Mariano Plotkin y Ricardo González Leandri, "El regreso a la democracia y la consolidación de nuevas élites intelectuales. El caso de Punto de Vista. Revista de cultura. Buenos Aires (1978-1985)", en Localismo y globalización. Apuntes para una historia de los intelectuales en Iberoamérica, ed. Mariano Plotkin y Ricardo González Leandri (Madrid: Consejo Superior de Investigaciones Científicas, 2000), 217-240; Leonardo Gustavo Vulcano, "Crítica, resistencia y memoria en Punto de Vista. Revista de cultura.", Orbis Tertius 4, no 7 (2000): 105-115; Roxana Patiño, "Punto de Vista, la persistencia de un debate", Revista Interamericana de Bibliografía 48, nº 1 (1998): 159-162. 
periódicas sobre la guerra, haciendo énfasis en las intervenciones del grupo editor de Punto de Vista.

Cabe destacar aquí que en algunos trabajos recientes sobre el campo cultural de la transición se ha argumentado que el año 1981 marcó el inicio de una apertura política en el país, en tanto la censura disminuyó y comenzaron a aparecer signos de oposición política al régimen. ${ }^{14}$ Mientras que algunas nuevas revistas salían a la luz durante estos años, otras que habían empezado a circular antes de 1981 adoptaron un lenguaje de explícito rechazo al régimen militar. En paralelo, una nueva ola cultural distintiva de la década de los ochenta empezó a emerger en estos años, constituida por nuevos fenómenos que abarcaban tanto la consolidación y auge del llamado rock nacional como movimientos contraculturales.

Este clima propició que un número reducido de intelectuales, como aquellos que durante estos años publicaron Punto de Vista, pudieran manifestar su oposición a la guerra en 1982. Dicha revista fue una de las publicaciones periódicas más relevantes de estos años y lo sería aún más luego de la transición a la democracia. Fundada por Carlos Altamirano, Ricardo Piglia y Beatriz Sarlo en 1978 de forma clandestina, y cuyos primeros números fueron secretamente financiados por la organización de izquierda maoísta Vanguardia Comunista, Punto de Vista se consolidaría como una de las publicaciones más importantes del campo intelectual argentino de fines de siglo veinte. Según Roxana Patiño, fue la revista hegemónica dentro del campo de las publicaciones culturales de los ochenta ${ }^{15}$ y para Luis Alberto Romero fue «el punto de referencia para toda una franja cultural y política de nuestra sociedad». ${ }^{16}$ A lo largo de sus treinta años, la revista publicó sofisticados ensayos de crítica literaria, cultural, estética, de historia de las ideas y de los intelectuales, de sociología cultural y política, de análisis cultural y de los medios masivos. Se destacó por haber introducido los estudios culturales en Argentina en los tempranos ochenta y por los cuidadosos ensayos sobre política y cultura que escribieron para sus páginas los más reconocidos intelectuales argentinos de fin de siglo veinte, entre quienes se destacan, además de los editores de la revista ya mencionados, José "Pancho" Aricó, Juan Carlos Portantiero, Hilda Sábato, Tulio Halperín

14 Ver, por ejemplo, Emmanuel Nicolás Kahan, Memories that lie a little: Jewish experiences during the Argentine dictatorship (Boston: Brill, 2019), 217; Milanesio, jDestape! sex, 27-28.

15 Roxana Patiño, Intelectuales en transición. Las revistas culturales argentinas (1981-1987) (São Paulo: Universidade de São Paulo, 1997), 23.

16 Luis Alberto Romero citado en Eduardo Pogoriles, "Después de 30 años, cerró la revista Punto de Vista”, Clarín, 3 de abril de 2008, https://www.clarin.com/sociedad/despues-30-anos-cerro-revista-punto-vista_0_ry7MP5pCTKl. html. 
Donghi y José Nun. La revista también se destacó por su postura consistente contra el nacionalismo fomentado por la Guerra de Malvinas, no sólo en los tempranos ochenta, sino también en los años subsiguientes, en tanto sus editores no cesaron de reflexionar sobre dicho episodio.

Cabe destacar que Punto de Vista era aún en 1982 una revista prácticamente clandestina y con una circulación baja en comparación con otras publicaciones periódicas independientes de la época. Por ende, antes de pasar a su análisis, una breve descripción de las reacciones de algunas otras revistas a la aventura militar en las Malvinas nos permitirá comprender el modo en que el previamente mencionado «cepo patriótico» influyó ampliamente el campo de la cultura argentina durante los meses de la guerra.

Una de las publicaciones independientes más populares y contestatarias de estos años fue Humor registrado (1978-1999), una revista humorística caracterizada por sus cómics e historietas que parodiaban celebridades, políticos y militares. Aunque Humor tenía un tono burlesco, cada entrega incluía algunos artículos o entrevistas en las que el humor se encontraba ausente y donde escritores, periodistas, políticos o figuras prominentes de la cultura expresaban su oposición al régimen. Si bien Humor se constituyó como una publicación contestaria al régimen, en el contexto de la Guerra de Malvinas la revista reivindicó el derecho de Argentina sobre las islas y evitó criticar al gobierno. Mara Burkart ha señalado que durante los meses que duró la guerra, Humor dejó de satirizar a las autoridades militares argentinas y comenzó a caricaturizar a los ingleses y que su posición frente a la guerra. ${ }^{17}$ Burkart también señala que «la posición de Humor frente a la guerra se caracterizó por un delicado equilibrio entre su perfil crítico y la no oposición a la guerra», una ambigüedad que le costó ventas a la revista, puesto que sus lectores esperaban un apoyo más contundente a la aventura militar. ${ }^{18}$

Hacia el final del período dictatorial, El Porteño (1982-1993) también se convirtió en una voz crítica de peso dentro del ámbito cultural argentino. Publicada de manera mensual y explícitamente fundada como una revista de izquierda y de oposición al régimen, El Porteño se enfocó en temas que eran bastante novedosos para la izquierda argentina, tales como el feminismo, la diversidad sexual, las drogas y la música de rock. En el caso de Malvinas, El Porteño tuvo una postura un tanto ambigua y evitó alinearse claramente con alguna de las posiciones en pugna, lo que no evitó disputas internas. La revista

17 Burkart, "Avatares de la crítica", 9.

18 Burkart, "Avatares de la crítica", 15. 
incluyó el tema Malvinas en sus páginas, pero no se decidió a rechazar o apoyar frontalmente la guerra, lo que produjo tensiones dentro del grupo editor. Según el testimonio de Gabriel Levinas, su director, «el peor momento para la revista fue, sin dudas, la Guerra de las Malvinas, había distintas opiniones sobre el tema, mi opinión personal era ir en contra. Pero todos me decían que no se podía, estábamos en guerra con los ingleses. Yo les decía que de la mano de estos tipos [los militares] no iba ni a la esquina. Era una reivindicación justa en manos de criminales. La revista en ese momento casi cerró». ${ }^{19}$

El testimonio de Levinas ejemplifica el «cepo patriótico» del que hablaba Alfonsín. En efecto, tan impopular era oponerse al conflicto que estas revistas tuvieron que matizar sus críticas al régimen, no sólo porque el sentimiento popular se había volcado a favor de la guerra, sino también porque al interior de estas publicaciones surgieron posturas divergentes. Como se mencionó, había dos lógicas en conflicto en lo que respecta a este tema: mientras que quienes apoyaban la ofensiva contra el Reino Unido exaltaban los valores patrióticos y la consideraban una lucha popular, una minoría se oponía a ésta en base a un rechazo al nacionalismo fomentado por el régimen militar, considerándola una maniobra para obtener legitimidad política. En este contexto, hubo cierto silenciamiento de las posturas disidentes y numerosos intelectuales de izquierda se sumaron al sentimiento nacionalista prevalente.

Los intelectuales de Punto de Vista se destacaron por su posición minoritaria en explícito rechazo a la guerra. El primer escrito en el que varios de los editores de la revista manifestaron su posición fue en una declaración publicada en otra revista independiente, Nueva Presencia (1977-1993), dirigida por Herman Schiller y vinculada a la comunidad judía no ortodoxa de Buenos Aires. ${ }^{20}$ Los miembros de Punto de Vista Carlos Altamirano, María Teresa Gramuglio y Beatriz Sarlo, junto con Luis Navalesi, Jorge Goldenberg y Juan Pablo Renzi firmaron la declaración "Paz inmediata y negociación. Única victoria del pueblo", publicada en Nueva Presencia el 25 de mayo de $1982 .{ }^{21}$ Refiriéndose

19 Gabriel Levinas, entrevistado por Ruben Matos. “Gabriel Levinas: De El Porteño hasta Twitter”, Periodismo en Blog , 18 de agosto de 2011, https:/ / rubenmatos.wordpress.com/2011/08/17/gabriel-levinas-de-el-porteno-hastatwitter/.

20 Nueva Presencia fue una de las publicaciones opositoras a la dictadura, sobre todo desde el año 1981, cuando la revista comenzó a incorporar denuncias por las desapariciones de personas y se alineó con el reclamo por los derechos humanos en Argentina. En su estudio sobre las organizaciones judías durante el Proceso, Nicolás Kahan señala que esta revista incluyó varias notas sobre el tema Malvinas, en especial en relación con las manifestaciones suscitadas por el conflicto y con las colectas de fondos para enviar a los soldados en las islas. Kahan, Memories that lie a little, 221.

21 El documento se reproduce en Beatriz Sarlo, Viajes: de la Amazonia a las Malvinas (Buenos Aires: Seix Barral, 2014), 251-260. 
al director de la publicación, Sarlo sostuvo que «la valentía de Schiller hizo que se publicara una síntesis [del documento] con nuestras firmas». ${ }^{22}$

El documento condenaba fuertemente la acción militar en las islas y acusaba al gobierno autoritario de hacer un uso del legítimo reclamo por la soberanía de una manera «manipulativa» para preservar su poder. También acusaba a los sindicatos y a los partidos políticos de no exigir el cese del conflicto y de justificar la lógica del gobierno al no prestar atención «al quién, al por qué y al cuándo» de la guerra. Más aún, condenaba la aventura militar como una manera de consolidar una imagen positiva en la esfera doméstica, en tanto se denunciaba que el gobierno intentaba esconder los graves problemas económicos que enfrentaba la Argentina al embarcarse una guerra que no había «caído del cielo», sino que era resultado de una «opción política» y, según rezaba el documento, «de ella se puede salir sin renunciar a los derechos argentinos sobre Malvinas». La declaración también denunciaba el clima nacionalista que se había generado y acusaba a los medios de comunicación de tergiversar los hechos: «la propaganda oficial ha jugado con sentimientos nacionalistas y antiimperialistas profundos clausurando al mismo tiempo todo interrogante sobre quién, por qué y en qué momento se decide el operativo militar (...) el pueblo fue mal informado y, desde los medios de comunicación de masas, se escenificó una fiesta más acorde con un mundial de fútbol que con el enfrentamiento bélico ya iniciado». El texto cerraba con una declaración contundente que proclamaba que «la suerte de la verdadera soberanía nacional y el correlativo derecho del pueblo argentino a autodeterminarse se decide frente al régimen militar que lo ha oprimido durante estos seis años».

De acuerdo con esta postura, los términos de la discusión se invertían: el enemigo del pueblo no era el Reino Unido, sino el gobierno militar argentino. Era este último el que obturaba la posibilidad de que el pueblo fuera soberano, según el principio de autodeterminación, dentro todo el territorio argentino. La declaración trasladaba la cuestión de la soberanía desde las islas al país entero, al sostener que era una contradicción en los términos hablar de un país soberano cuando el principio de autodeterminación se había perdido bajo el régimen militar, antidemocrático y autoritario. En otras palabras, no se podía entender que el país fuera soberano bajo una dictadura, por tanto, era cuanto menos engañoso defender en tal contexto el reclamo por las islas, lo que, a su vez, implicaba conferirle cierto aval al régimen autoritario. 
Soberanía y democracia se presentaban, así, como dos caras de una misma moneda, y se denunciaba que bajo la dictadura los ciudadanos argentinos no podían gozar de ninguna de las dos.

Ahora bien, el texto publicado en Nueva Presencia se puede comprender mejor a la luz de otra declaración que días después del inicio de la guerra había publicado un grupo de exiliados argentinos en México favorable a la ofensiva argentina. Como ha señalado Pablo Yankelevich en un estudio fundamental sobre el exilio argentino en México, quienes llegaron al país del norte se agruparon en organizaciones que mantuvieron a la comunidad dentro de estructuras de contención bastante cerradas y formaron asociaciones en las cuales se reunían periódicamente y discutían las noticias que llegaban de Argentina. ${ }^{23}$ Uno de estos grupos, el llamado Grupo de Discusión Socialista, en el cual participaban importantes intelectuales, tales como José Aricó, Juan Carlos Portantiero y Emilio de Ípola, publicó una declaración el 10 de mayo de 1982 en apoyo a la guerra que vale analizar para entender la lógica en que se basaba la posición de este sector de la izquierda intelectual.

El documento, titulado "Por la soberanía argentina en las Malvinas, por la soberanía popular en la Argentina", argumentaba que, a pesar de que un gobierno ilegítimo estaba llevando al país a una guerra, la demanda por la soberanía era enteramente legítima. ${ }^{24} \mathrm{El}$ dominio británico sobre el archipiélago se entendía como un residuo del colonialismo inglés y, por lo tanto, se sostenía que la izquierda debía oponerse al Reino Unido independientemente de otras distinciones. En sus primeras páginas, el texto proponía que no se trataba de elegir entre el mejor de los males — es decir, entre los militares argentinos y Margaret Thatcher_— sino de apoyar un reclamo legítimo del pueblo argentino contra el colonialismo británico. Las oraciones finales del documento llamaban a un cese al fuego, pero también a la restauración de la soberanía argentina sobre las islas: «Llamamos a todas las fuerzas progresistas del mundo para que se movilicen por el inmediato cese de la agresión imperialista en las Malvinas (...) Adherimos a todos los sectores populares de Argentina que luchan para que no sea entregada una

\footnotetext{
23 Para este tema ver Pablo Yankelevich, Ráfagas de un exilio: argentinos en México, 1974-1983 (México, D.F: Colegio de México, 2009).

24 El documento se reproduce en León Rozitchner, Las Malvinas: de la guerra "sucia” a la guerra "limpia" (Buenos Aires: Centro Editor de América Latina, 1985), 143-155. Los firmantes de este documento fueron José Aricó, Sergio Bufano, Agustina Fernández, Gregorio Kaminsky, Ana María Kaufman, Ricardo Nudelman, Marcelo Pasternak, Rafael Pérez, Olga Pisani, Gloria Rojas, Norma Sinay, Jorge Tula, Haydée Birgin, Emilio De Ípola, Néstor García Canclini, Mirta Kaminsky, Pedro Levin, José Nun, Ana María Pérez, Osvaldo Pedroso, Juan Carlos Portantiero, Nora Rosenfeld, Enrico Stefani, Carlos Tur y Sergio Sinay.
} 
soberanía que se está reconquistando con la sangre y el esfuerzo del pueblo». En síntesis, la declaración afirmaba que la demanda argentina era parte de una lucha popular y, por lo tanto, que el origen del conflicto debía de diferenciarse de su legitimidad y suponía que los actores involucrados sabían distinguir entre estas dos instancias. En definitiva, el documento ponía en segundo plano las razones por las que el régimen militar había declarado la guerra y expresaba una posición antiimperialista y anticolonialista, condenando fuertemente al Reino Unido.

Cabe aclarar que el desacuerdo sobre el tema Malvinas entre el documento de Nueva Presencia y el del Grupo de Discusión Socialista no versaba sobre la cuestión de la legitimidad del reclamo soberano y la necesidad de poner fin al conflicto, temas sobre los que ambos grupos coincidían. Más bien, la divergencia radicaba en el énfasis que se hacía entre los orígenes del conflicto y su justificación en una lucha antiimperialista. Mientras que los argentinos en México hacían hincapié en los aspectos legítimos del conflicto y dejaban traslucir una lógica nacionalista y de lucha popular contra el imperialismo, aquellos que permanecieron en Buenos Aires le otorgaban más peso al contexto en el cual el conflicto se había originado, dando lugar a un rechazo mucho más explícito de la guerra.

Esta divergencia de posturas suscitó el envío de una carta de parte de Beatriz Sarlo al grupo de exiliados en México, con quien ella y sus colegas en Argentina habían comenzado a establecer una asidua comunicación. ${ }^{25}$ Fechada el 3 de junio de 1982, la carta de Sarlo objetaba el documento de los exiliados en México, sosteniendo que «ustedes creen que es un obstáculo epistemológico para entender el actual conflicto referirse exclusivamente a sus orígenes. Yo diría que igualmente peligroso es guiarse exclusivamente por los deseos». ${ }^{26}$ Sarlo señalaba que la aventura de las Malvinas no podía separarse de sus orígenes en el contexto de la dictadura y, de manera clara, acusaba a los argentinos en México de haberse dejado llevar por sus deseos de unirse a una causa popular al mismo tiempo que hacían caso omiso de los factores contextuales. Sarlo también les advertía que, si había algo que estaba ausente en la situación política, era la posibilidad de hacer diferenciaciones: «¿Qué

25 A partir de 1980, Altamirano, Sarlo y el grupo de exiliados argentinos en México comenzaron a establecer una comunicación asidua, fomentada en parte por un viaje que Altamirano realizó al país del norte en 1980 y otro de Sarlo en 1981. A su regreso a Argentina luego de la transición, algunos de estos intelectuales como José Aricó y Juan Carlos Portantiero, se unieron al consejo editor de Punto de Vista. Ver Sofía Mercader y Diego García, "Entrevista a Beatriz Sarlo", Artepolítica (blog), 26 de julio de 2013, http://artepolitica.com/articulos/entrevista-a-beatriz-sarlo/. 26 Esta carta se encuentra reproducida en Sarlo, Viajes, 246-251. 
quieren decir ustedes con "ha sabido y sabe diferenciar"? (...) Diferenciar, precisamente es lo que no se hizo. (...) La plaza [de Mayo] del 2 de abril estaba sometida a la manipulación triunfalista de la dictadura y celebró la recuperación de las Malvinas como un hecho consumado». ${ }^{27}$ Sarlo acusaba así a sus colegas en el exilio de haber sido ciegos a las circunstancias que rodearon la ofensiva militar y de confundir el conflicto con una «lucha populan».

Estas dos declaraciones, la de Nueva Presencia y la del Grupo de Discusión Socialista representan las dos posturas centrales que se dieron en el ámbito de la izquierda intelectual respecto de la Guerra de Malvinas. Estas disputas no tuvieron motivo de continuarse por mucho tiempo dada la brevedad del conflicto. Como se mencionó, derrotados los militares hacia mediados de 1982, no tuvieron otra alternativa que llamar a elecciones y negociar con los partidos políticos una salida democrática.

La Guerra de Malvinas, sin embargo, continuó siendo objeto de debate en las páginas de Punto de Vista, dando lugar a importantes análisis por parte de sus editores. En octubre de 1982, a unos meses de concluida la guerra, Carlos Altamirano publicó un texto fundamental en la revista en donde se ubicaba al tema Malvinas como un episodio que debía reevaluarse a la luz de los hechos y de las posiciones que los intelectuales habían adoptado en dicha coyuntura. El texto de Altamirano polemizaba con aquellos que, desde la izquierda, habían apoyado la guerra: «en cuanto a los que se propusieron reapropiarse del conflicto para darle una orientación radical, asimilándolo a una guerra de liberación nacional, únicamente lograron encrespar sus propias declaraciones. Quienes disponían del poder no sólo tenían otras ideas respecto del sentido y los límites que debía tener el conflicto, sino los medios que el poder, precisamente, confiere para implantarlos» ${ }^{28}$ Altamirano indicaba que el error de sus colegas había sido el de pretender ver en el conflicto de Malvinas una reedición de la lucha popular y del tipo de discurso revolucionario característico de la izquierda en los años previos a la dictadura. La oración final de su ensayo transmitía el grado al que una nueva dicotomía comenzaría a jugar un rol preponderante en la transición, aquella de autoritarismo versus democracia: «Pero no hay otro camino tampoco para la "cuestión nacional": la historia de nuestro país la ha anudado inextricablemente con la "cuestión democrática” y ninguna puede resolverse verdaderamente sin la otra». 
En este pasaje, Altamirano ponía en relación el eje de la cuestión nacional (y Malvinas evoca sentimientos nacionalistas por excelencia) con la cuestión democrática. Apoyar la guerra había sido una posición miope: no se podía olvidar que el origen del conflicto estaba ligado a un régimen dictatorial, el más represor de la larga seguidilla de dictaduras del siglo veinte en Argentina. De alguna manera, una idea contra fáctica pesaba en el análisis de Altamirano: si los militares hubieran ganado la guerra, ¿habría habido transición? La respuesta era de suma importancia, puesto que no sólo se trataba del final de la dictadura instaurada en 1976, sino del final de ciclos de autoritarismo político que era urgente dejar atrás.

Aquí cabe destacar que, pese a la derrota en la Guerra de Malvinas — o más bien gracias a ella_— los militares se vieron obligados a llamar a elecciones, dando comienzo a la transición. Las elecciones se celebraron el 30 de octubre de 1983, luego de siete años de dictadura. El candidato de la Unión Cívica Radical, Raúl Alfonsín, quien se había opuesto a la guerra y quien había prometido enjuiciar a los militares durante su campaña, fue electo presidente, dando comienzo a un hasta ahora ininterrumpido período de estabilidad democrática en el país. La derrota de Malvinas dio lugar a un tipo de transición por colapso, según la ya clásica clasificación propuesta por Guillermo O’Donnell. ${ }^{29}$ Este tipo de transición implicó que, a diferencia del caso chileno y uruguayo en donde la transición fue pactada, los militares dejaran el poder con escaso margen de negociación, lo que determinó en gran medida que fueran enjuiciados por crímenes de lesa humanidad a tan solo dos años de dejar el poder. Es decir que, de algún modo, la derrota de Malvinas precipitó la salida de los militares y condujo a una transición rápida, bajo un gobierno que rindió cuentas con el pasado autoritario a través de los juicios a las juntas militares, celebrados en $1985 .^{30}$ En este sentido, el artículo de Altamirano en Punto de Vista remarcaba la necesidad de revisar el nacionalismo fomentado por Malvinas y rechazarlo de plano, puesto que la prioridad era en 1982 enfrentar a los militares y proponer una salida democrática para el país. La posición de Punto de Vista jerarquizaba la cuestión de la democracia por sobre el patriotismo que Malvinas había generado, alineándose así con una subjetividad antinacionalista.

29 Guillermo A. O’Donnell, “Introduction”, en Transitions from authoritarian rule. Latin America, ed. Guillermo A. O’Donnell et al. (Baltimore: Johns Hopkins University Press, 1986), 3-18.

30 Sobre este tema ver Carlos Santiago Nino, Radical Evil on Trial (Conn / London: Yale University Press, 1996); Carlos Acuña y Catalina Smulovitz, "Militares en la transición argentina: del gobierno a la subordinación constitucional", en Juicio, castigos y memorias: derechos humanos y justicia en la política argentina, ed. Carlos Acuña (Buenos Aires: Ediciones Nueva Visión, 1995), 21-90. 
En cuanto a las disputas con colegas intelectuales de izquierda, el desacuerdo se disolvió rápidamente. El espacio de sociabilidad que se había empezado a construir entre los miembros del Grupo de Discusión Socialista y los miembros de Punto de Vista siguió su curso y, cuando los intelectuales exiliados regresaron a Argentina, todos ellos fundaron una institución clave durante la transición, el Club de Cultura Socialista. ${ }^{31}$ El tema de Malvinas no generó nuevas discusiones y, más bien, los argentinos que comenzaron a regresar del exilio se retractaron de sus dichos sobre Malvinas. Por ejemplo, Emilio de Ípola, firmante de la declaración del Grupo de Discusión Socialista, sostuvo muchos años después que «desde México, habíamos sacado una declaración imperdonable (...) Todavía no logro explicarme cómo [la] pudimos escribir. Si me preguntan ahora de Malvinas, yo me niego a hablar, porque ya lo hice y mal, así que prefiero que hablen otros».32

\section{La Guerra de Malvinas en la posdictadura}

Punto de Vista fue reconocida como una publicación crítica en el contexto de la Guerra de Malvinas y durante los años que siguieron a la transición a la democracia, la revista siguió haciendo referencia a este episodio de la vida política argentina, remarcando la relación entre la derrota argentina y el fin de la dictadura. Por ejemplo, en un artículo de noviembre de 1994, Altamirano recordaba el tema Malvinas con la siguiente pregunta: «¿Quién hubiera esperado en 1981 que la democracia se abriría paso por la brecha abierta por una guerra y una derrota frente a Inglaterra?». ${ }^{33}$ En ese mismo número de Punto de Vista, un artículo de Sarlo sobre intelectuales y política comenzaba con una frase que categóricamente condenaba el momento nacionalista durante la guerra: «Nunca, ni antes ni después, me sentí tan salvajemente separada de la sociedad argentina como en los meses de la Guerra de Malvinas. Una Plaza de Mayo obnubilada había recibido, con una especie de paroxismo nacionalista, la invasión ordenada por Galtierì. ${ }^{34}$ Sarlo señalaba allí también

31 Pablo Ponza, "El Club de Cultura Socialista y la gestión Alfonsín: transición a una nueva cultura política plural y democrática.", Nuevo mundo. Mundos nuevos, 15 de febrero de 2013.

32 Entrevista con Emilio de Ípola en Javier Trímboli, ed., La Izquierda en la Argentina: conversaciones (Buenos Aires: Manantial, 1998), 153.

33 Carlos Altamirano, "El orden y el movimiento", Punto de Vista, no 50 (noviembre de 1994): 2-4.

34 Beatriz Sarlo, "¿La voz universal que toma partido? Crítica y autonomía", Punto de Vista, no 50 (noviembre de 1994): 5-9. 
que, en ese momento, el discurso crítico de los intelectuales había «perdido audibilidad» y que ella y sus colegas estaban «demasiado lejos» del resto de la sociedad y de aquellos intelectuales que habían decidido apoyar el conflicto. Estas referencias en ensayos sobre historia reciente argentina demuestran que, para los intelectuales en Punto de Vista, la cuestión Malvinas debía ser pensada y rememorada como un episodio desafortunado en que la sociedad argentina prestó apoyo a los militares, pero que también precipitó el final de la dictadura dando lugar a la experiencia democrática. En otras palabras, debía ponerse a la guerra en el contexto de los primeros años de la década del ochenta y no olvidarla ni separarla de la historia como un episodio desligado de su origen en la dictadura de 1976. Debía, al mismo tiempo, reconocerse la complicidad con los militares de parte de la sociedad civil, de los partidos políticos, de los medios de comunicación y de los intelectuales en dicha coyuntura y condenarse dicho episodio desafortunado de la historia reciente.

Sin embargo, hasta el presente, el «problema Malvinas» no tiende a ser complejizado en el discurso político, ni tampoco ha tenido lugar una revisión demasiado profunda de lo que significó el apoyo a la guerra por grandes sectores de la población en los años finales de la dictadura. El conflicto de 1982 exacerbó el sentimiento nacionalista y opositor al Reino Unido y son pocas las voces que piden revisar ese momento de patriotismo a destiempo que suscitó la guerra. En particular, la visión de Beatriz Sarlo resulta interesante puesto que durante años ha polemizado con otros intelectuales sobre este tema y ha insistido en la idea de reevaluar la experiencia de Malvinas en relación con la democracia. Es Sarlo quien, de todos los intelectuales aquí mencionados, ha asumido con más decisión una posición de «intelectual pública», participando de los debates del día a través de intervenciones en los medios de comunicación de masas.

En sus más recientes intervenciones sobre este tema, Sarlo insistió en ubicar el tema Malvinas dentro del contexto de la dictadura. Por ejemplo, en una participación de 2011 en el programa de televisión 678, exigió repensar el conflicto para construir una mejor «política de memoria» en Argentina, sosteniendo — como lo había hecho anteriormente desde las páginas de Punto de Vista- que «le debemos a los muertos de Malvinas la democracia. Todo el nacionalismo patriótico de izquierda, de centro y de derecha que apoyó la Guerra de Malvinas tiene que reflexionar. Cuando hablamos de memoria también hay que introducir Malvinas. Esa guerra perdida hizo que ganáramos la democracia. (...) Es una memoria que tenemos que activar porque ahí 
hubo responsabilidad popular en plegarse a esa guerra». ${ }^{35} \mathrm{Al}$ igual que en 1982, Sarlo hizo énfasis en la complicidad de la sociedad con los militares, incluidos sindicatos, partidos políticos e intelectuales. La «lógica nacionalista» había vencido cualquier tipo de reflexión sobre el «por qué, cuándo y quién» de la guerra.

Por último, en 2012 Sarlo junto a otro grupo de intelectuales (entre quienes se encontraban varios de sus antiguos compañeros de Punto de Vista) firmó un documento defendiendo el principio de autodeterminación de los pueblos en el caso de las Malvinas. ${ }^{36}$ Allí, estos intelectuales declaraban que creían que «la opinión pública argentina está madura para una estrategia que concilie los intereses nacionales legítimos con el principio de autodeterminación sobre el que ha sido fundado este país». ${ }^{37} \mathrm{La}$ declaración argumentaba que los habitantes de las Malvinas debían ser parte de las negociaciones que tendrían como objetivo la solución del conflicto, un tema que la posición oficial argentina no suele tomar en cuenta. Sin embargo, esta declaración sólo sirvió para generar polémica en la opinión pública argentina, pero no para modificar nociones y discursos sobre las Malvinas.

35 678-24-05-11 (2 de 4), accedido 18 de octubre de 2020, https://www.youtube.com/watch?v=i9ntzsGXGDM\&ab_ channel $=$ Televisi $\% \mathrm{C} 3 \% \mathrm{~B} 3 \mathrm{nP} \% \mathrm{C} 3 \%$ BAblica.

36 El documento se acompañaba de las siguientes firmas: Jorge Lanata, Juan José Sebreli, Emilio de Ípola, Pepe Eliaschev, Rafael Filippelli, Roberto Gargarella, Fernando Iglesias, Santiago Kovadloff, Gustavo Noriega, Marcos Novaro, José Miguel Onaindia, Vicente Palermo, Eduardo Antin (Quintín), Luis Alberto Romero, Hilda Sábato, Daniel Sabsay y Beatriz Sarlo.

37 "Una visión alternativa sobre la causa de Malvinas", La Nación, 23 de febrero de 2012, https://www.lanacion. com.ar/politica/una-vision-alternativa-sobre-la-causa-de-malvinas-nid1450787/. 
Se analizó el lugar de la revista Punto de Vista dentro del campo intelectual argentino y se examinaron las declaraciones publicadas por sus miembros tanto en las páginas de la revista, como en otras publicaciones de la época y en correspondencias personales. Se hizo particular énfasis en la discusión sostenida por miembros de Punto de Vista y el Grupo de Discusión Socialista, compuesto por intelectuales exiliados en México. El motivo principal de esta disputa se basaba en una diferente interpretación del conflicto bélico: mientras que aquellos intelectuales que habían permanecido en Buenos Aires se opusieron vehementemente a la guerra, bajo el argumento de que se trataba de una manipulación de los militares para obtener apoyo popular y legitimarse ante la sociedad, los intelectuales en México sostenían que la causa Malvinas iba más allá de los factores contextuales y que debía defenderse la soberanía argentina en las Malvinas en dicha coyuntura. Finalmente, el artículo analizó cómo el grupo de Punto de Vista intentó mantener una discusión acerca de Malvinas en los años posteriores a la transición, puesto que sus intelectuales juzgaban imprescindible revisar ese momento de máximo nacionalismo que, por unos meses, obturó toda crítica al régimen militar.

En última instancia, la disputa entre una «lógica militarista y nacionalista» contra la «subjetividad antinacionalista» sostenida por Punto de Vista se evidencia en las intervenciones públicas de sus editores durante y después del conflicto. Se hizo énfasis en cómo el legítimo sentimiento relacionado con la soberanía argentina sobre un territorio largamente ocupado por el Reino Unido derivó en una exaltación nacionalista hábilmente usufructuada por los militares. El desenlace fue trágico, en tanto cientos de jóvenes soldados perdieron la vida y otros cientos tuvieron sufrieron las terribles condiciones del clima de las islas y la falta de provisiones, mientras la sociedad argentina creyó por varios meses en una posible victoria alimentada por la imagen trasmitida por los medios de comunicación de masas.

Podría decirse que el tema Malvinas está lejos de haberse cerrado. Por una parte, el reclamo argentino de soberanía sobre las islas sigue abierto y sin resolución, lo que se vislumbra aún más problemático si se tiene en cuenta la voluntad de los habitantes de las islas, quienes eligieron permanecer bajo dominio británico en un referéndum celebrado en 2013. Por otra parte, a nivel de la memoria colectiva, el tema no ha generado un consenso tan claro respecto de Malvinas como el que felizmente se constituyó en relación con el rechazo a la dictadura militar. Como escribió la historiadora Hilda Sábato en Punto de Vista diez años después de la transición a la democracia: «la compleja pregunta sobre la responsabilidad colectiva ocupa un lugar importante en 
algunas reflexiones (...) Insistir en revisar esa parte de la historia quizás sea la mejor manera de trabajar contra el olvido». ${ }^{38}$

\section{Bibliografía}

678 - 24-05-11 (2 de 4). Accedido 18 de octubre de 2020. https://www.youtube.com/watch?v=i9ntzsGXGDM\&ab_channel=Televisi $\% \mathrm{C} 3 \% \mathrm{~B} 3 \mathrm{nP}$ $\% \mathrm{C} 3 \%$ BAblica.

Acuña, Carlos, y Catalina Smulovitz. "Militares en la transición argentina: del gobierno a la subordinación constitucional". En Juicio, castigos y memorias: derechos bumanos y justicia en la política argentina, editado por Carlos Acuña, 21-90. Buenos Aires: Ediciones Nueva Visión, 1995.

Altamirano, Carlos. "El orden y el movimiento". Punto de Vista, no 50 (noviembre de 1994): 2-4.

Altamirano, Carlos. "Lecciones de una guerra". Punto de Vista, no 15 (octubre de 1982): 3-5.

Avellaneda, Andrés. "Argentina militar: Los discursos del silencio". En Literatura argentina hoy: de la dictadura a la democracia, editado por Karl Kohut y Andrea Pagni, 10-30. Frankfurt am Main: Vervuert, 1993.

Bonnet, Alberto. "La izquierda argentina y la guerra de las Malvinas". Razón y Revolución, $\mathrm{n}^{\circ} 3$ (7 de septiembre de 2014). http://www.revistaryr.org. ar/index.php/RyR/article/view/456.

Burkart, Mara E. "Avatares de la crítica y de la sátira: HUMOR y la Guerra de Malvinas". Nuevo mundo, Mundos nuevos, 7 de febrero de 2013. https:// doi.org/10.4000/nuevomundo.64808.

Calveiro, Pilar. Poder y desaparición: los campos de concentración en Argentina. Buenos Aires: Colihue, 1998.

Crenzel, Emilio A. La historia politica del Nunca más: la memoria de las desapariciones en la Argentina. Buenos Aires: Siglo Veintiuno Editores, 2008. 
Gamarnik, Cora. "La fotografía de prensa durante la guerra de Malvinas: la batalla por lo (in)visible". Páginas: Revista Digital de la Escuela de Historia 7 , n 13 (2015): 79-117.

Gente no 876 (7 de mayo de 1982).

"Informe sobre la situación de losderechos humanos en Argentina". Comisión Interamericana de Derechos Humanos. Organización de los Estados Americanos. http://www.cidh.oas.org/countryrep/Argentina80sp/ indice.htm.

Jelin, Elizabeth. Los trabajos de la memoria. Madrid: Siglo Veintiuno Editores, 2002.

Kahan, Emmanuel Nicolás. Memories that lie a little: Jewish experiences during the Argentine dictatorship. Traducido por David William Foster. Leiden / Boston: Brill, 2019.

King, John. "Las revistas culturales de la dictadura a la democracia: el caso de Punto de Vista". En Literatura argentina hoy: de la dictadura a la democracia, editado por Karl Kohut y Andrea Pagni, 87-94. Frankfurt: Vervuert, 1993.

Levinas, Gabriel, entrevistado por Ruben Matos. "Gabriel Levinas: De El Porteño hasta Twitter.", Periodismo en Blog, 18 de agosto de 2011. https:// rubenmatos.wordpress.com/2011/08/17/gabriel-levinas-de-el-porteno-hasta-twitter/.

Mercader, Sofía. "Notas sobre la historia de la revista Punto de Vista (19782008) y su colocación en el campo intelectual argentino de fin de siglo". Nuevo mundo. Mundos nuevos, 16 de febrero de 2018. https://doi. org/10.4000/nuevomundo.72032.

Mercader, Sofía y Diego García. "Entrevista a Beatriz Sarlo". Artepolitica (blog), 26 de julio de 2013. http://artepolitica.com/articulos/entrevistaa-beatriz-sarlo/.

Milanesio, Natalia. ;Destape! sex, democracy, \& freedom in postdictatorial Argentina. Pittsburgh: University of Pittsburgh Press, 2019.

Moretti, Ignacio. "De silencios, diatribas y apoyos. Los intelectuales de izquierda frente a la Guerra de Malvinas". Estudios Sociales: Revista Universitaria Semestral 54, no 1 (2018): 169-192. 
Nino, Carlos Santiago. Radical Evil on Trial. New Haven, Conn / London: Yale University Press, 1996.

O’Donnell, Guillermo A. "Introduction". En Transitions from authoritarian rule. Latin America, editado por Guillermo A. O'Donnell, Philippe C. Schmitter, Laurence Whitehead, y Woodrow Wilson International Center for Scholars, 3-18. Baltimore: Johns Hopkins University Press, 1986.

Patiño, Roxana. Intelectuales en transición. Las revistas culturales argentinas (19811987). São Paulo: Universidade de São Paulo, 1997.

Patiño, Roxana. "Punto de Vista, la persistencia de un debate". Revista Interamericana de Bibliografía 48, no 1 (1998): 159-162.

Plotkin, Mariano, y Ricardo González Leandri. "El regreso a la democracia y la consolidación de nuevas élites intelectuales. El caso de Punto de Vista. Revista de cultura. Buenos Aires (1978-1985)". En Localismo y globalización. Apuntes para una bistoria de los intelectuales en Iberoamérica, editado por Mariano Plotkin y Ricardo González Leandri, 217-240. Madrid: Consejo Superior de Investigaciones Científicas, 2000.

Pogoriles, Eduardo. "Después de 30 años, cerró la revista Punto de Vista". Clarín, 3 de abril de 2008. https://www.clarin.com/sociedad/despues30-anos-cerro-revista-punto-vista_0_ry7MP5pCTKl.html.

Ponza, Pablo. "El Club de Cultura Socialista y la gestión Alfonsín: transición a una nueva cultura política plural y democrática". Nuevo mundo. Mundos nuevos, 15 de febrero de 2013. https://doi.org/10.4000/nuevomundo.65035.

Romero, Luis Alberto. Breve historia contemporánea de la Argentina. 1916-2016. México: Fondo de Cultura Económica, 2017.

Rozitchner, León. Las Malvinas: de la guerra "sucia" a la guerra "limpia". Buenos Aires: Centro Editor de América Latina, 1985.

Sabato, Hilda. "Historia reciente y memoria colectiva". Punto de Vista, $\mathrm{n}^{\circ} 49$ (agosto de 1994): 30-34.

Sarlo, Beatriz. "La memoria de la guerra de Malvinas sigue siendo inabordable como mito nacional. El patriotismo despótico". La Nación, 27 enero de 2012. https://www.lanacion.com.ar/opinion/el-patriotismo-despotico-nid1443722/. 
Sarlo, Beatriz. "¿La voz universal que toma partido? Crítica y autonomía”. Punto de Vista, no 50 (noviembre de 1994): 5-9.

Sarlo, Beatriz. Viajes: de la Amazonia a las Malvinas. Buenos Aires: Seix Barral, 2014.

Sheinin, David M. K. Consent of the Damned: Ordinary Argentinians in the Dirty War. Gainesville: University Press of Florida, 2013.

Svetliza, Exequiel. "La guerra de Malvinas y sus trincheras intelectuales: entredichos entre los editores de la revista Sitio y el escritor Néstor Perlongher". Remate de Males 37, no 2 (2017): 925-944. https://doi. org/10.20396/remate.v37i2.8648698.

Tarcus, Horacio. "Los dilemas de la izquierda en la Guerra de Malvinas". Página 12, 2 de abril de 2007.

Trímboli, Javier, ed. La Irquierda en la Argentina: conversaciones. Buenos Aires: Manantial, 1998.

"Una visión alternativa sobre la causa de Malvinas". La Nación, 23 de febrero de 2012. https:/ /www.lanacion.com.ar/politica/una-vision-alternativa-sobre-la-causa-de-malvinas-nid1450787/.

Veliz, Mariano. "Formas discrepantes de inteligibilidad de la Guerra de Malvinas: Jorge Denti y León Rozitchner entre el exilio y la subjetividad". Nuevo mundo Mundos nuevos, 8 de octubre de 2019. https://journals.openedition.org/nuevomundo/76985.

Vezzetti, Hugo. Pasado y presente: guerra, dictadura y sociedad en la Argentina. Buenos Aires: Siglo Veintiuno Editores, 2002.

Vulcano, Leonardo Gustavo. "Crítica, resistencia y memoria en Punto de Vista. Revista de cultura". Orbis Tertius 4, n 7 (2000): 105-115.

Yankelevich, Pablo. Ráfagas de un exilio: argentinos en México, 1974-1983. México: D.F: Colegio de México, 2009. 